Research Article

\title{
Modeling the Formation Mechanism of Food Safety Risk in Catering 020 Distribution Link
}

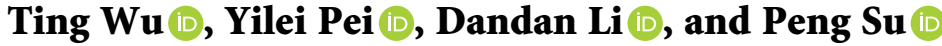 \\ Institution: Management College, Beijing Union University, Postal Address: 97 North Fourth Ring East Road, \\ Beijing 100101, China \\ Correspondence should be addressed to Yilei Pei; gltyilei@buu.edu.cn
}

Received 4 October 2021; Accepted 14 November 2021; Published 26 November 2021

Academic Editor: Daqing Gong

Copyright $\odot 2021$ Ting Wu et al. This is an open access article distributed under the Creative Commons Attribution License, which permits unrestricted use, distribution, and reproduction in any medium, provided the original work is properly cited.

This paper aims to solve the problem of food safety in catering $\mathrm{O} 2 \mathrm{O}$ distribution link. We applied the system dynamics method to model the formation mechanism of food safety risk in the distribution link. The results of our experiment include identifying the risk factors that may be faced by food safety in the distribution link from five perspectives: $\mathrm{O} 2 \mathrm{O}$ catering enterprise's own risk, logistics distribution team's distribution risk, $\mathrm{O} 2 \mathrm{O}$ catering platform supervision risk, user-supervision risk, and government department supervision risk, and establishing a risk index evaluation system based on the Analytic Hierarchy Process. With the help of the system dynamics model, the corresponding risk formation mechanism system model flow diagram is established, and the model simulation analysis is carried out. Through this research, we concluded that we can use the risk model to understand the risks faced by different subjects so as to make targeted countermeasures.

\section{Introduction}

In recent years, the economy of the traditional catering industry has been in recession. In order to find a new development path, more and more traditional catering enterprises choose to integrate with the Internet to realize online payment and offline consumption [1]. With the rapid development of the Internet plus era, catering $\mathrm{O} 2 \mathrm{O}$ distribution has become a new network catering mode, which has attracted wide attention. Meanwhile, the rise of catering $\mathrm{O} 2 \mathrm{O}$ is also slowly changing consumers' living habits. Consumers can get convenient takeout services at home by ordering and paying on a mobile app.

According to the $47^{\text {th }}$ statistical report on China's Internet Development released by China Internet Network Information Center (CNNIC), by December 2020, China's online takeout users had reached 419 million. Ele.me takeout, Meituan takeout, Baidu takeout, and other catering $\mathrm{O} 2 \mathrm{O}$ platforms also poured into the catering $\mathrm{O} 2 \mathrm{O}$ field. However, with the wholly-owned acquisition of Ele.me takeout by Alibaba, the competition among takeout industries is becoming more and more fierce, and food safety problems have been quickly exposed $[2,3]$. For example, the takeout packaging is plastic bags, the additives used do not meet the standard, and the food is deteriorated, which has attracted the extensive attention of the society and consumers.

The catering $\mathrm{O} 2 \mathrm{O}$ distribution link is related to the "safety on the tip of the tongue" of consumers and the "last mile" of food safety. Therefore, identifying and evaluating the possible risks in the catering $\mathrm{O} 2 \mathrm{O}$ distribution link and taking risk prevention and control measures will help to promote the healthy development of catering $\mathrm{O} 2 \mathrm{O}$.

\section{Literature Review}

As for food safety in catering $\mathrm{O} 2 \mathrm{O}$ distribution, many domestic and foreign scholars have analyzed the current situation of online food safety from different perspectives [4-7]. Some scholars also conducted a detailed analysis on specific problems existing in online food safety $[8,9]$ and some related studies on online food safety guarantee measures [10-12]. In view of the food safety problems in 
catering $\mathrm{O} 2 \mathrm{O}$ distribution link, scholars generally believe that the food safety risks in the catering $\mathrm{O} 2 \mathrm{O}$ distribution link are caused by the problems of deliverers [13], distribution box [14], traffic safety [15], and distribution mode [16]. Based on the grounded theory, Sheng and Qing [17] tried to find out various factors affecting takeaway food safety, such as takeaway platform, takeaway business, government regulation, and media supervision. Hua et al. [18] explored the evolution mechanism of Internet ordering regulatory countermeasures from the perspective of ordering platforms. In current studies on food safety risks, some scholars also use system dynamics theory to analyze consumers' perception of food safety risks [19], but there is no relevant research on food safety risks in the catering $\mathrm{O} 2 \mathrm{O}$ distribution link. Therefore, combined with the theory of system dynamics, this paper attempts to analyze the risks faced by multiple participants in food safety in catering $\mathrm{O} 2 \mathrm{O}$ distribution from a systematic perspective, further explore the causes of risk impact and the mechanism of interaction, and finally put forward relevant suggestions.

Based on scholars' relevant research on food safety risk in catering $\mathrm{O} 2 \mathrm{O}$ distribution $[20,21]$, this paper divides it into five risk factors: $\mathrm{O} 2 \mathrm{O}$ catering enterprise's own risk, logistics distribution team's distribution risk, $\mathrm{O} 2 \mathrm{O}$ catering platform supervision risk, user supervision risk, and government department supervision risk.

\subsection{Risks of Food Products of O2O Catering Enterprises.} The risks formed by the food products of $\mathrm{O} 2 \mathrm{O}$ catering enterprises mainly come from two aspects: the production and processing risks of food products and the packaging risks of food products. Among them, the risks of food production and processing include inadequate cleaning of overalls, inadequate disinfection of utensils, inadequate cleaning of food materials, unreasonable use of food additives, and insufficient attention of chefs to the order notes of orders. For example, Article 33 of China's food safety law mentions that food merchants should pay attention to personal hygiene and wear overalls. However, chefs who make meals will inevitably come into contact with bacteria at work. Therefore, if the overalls are not cleaned or disinfected for a long time, there will be more and more pollutants on the clothes, which will pose risks to the safety of meals. Disanto et al. [22] also believe that food safety largely depends on the behavior of catering personnel, such as food handlers. However, the risk of food packaging comes from poor food packaging materials and no label on the packaging box.

The positive feedback of $\mathrm{O} 2 \mathrm{O}$ catering enterprises' own risks includes irregular production and processing of food products, unreasonable use of food additives, and irregular packaging of food products, which are the reasons for increasing their own risks. The negative feedback includes standardizing the production and processing process of food products, using food additives appropriately and rationally, and using standardized and qualified packaging.
2.2. Distribution Risk of Logistics Distribution Team. In the process of catering $\mathrm{O} 2 \mathrm{O}$ distribution, there are risks in distribution personnel, distribution packaging, distribution tools, and distribution methods, leading to distribution risks in the whole logistics and distribution team. The risks of delivery personnel pointed out here include the health status of delivery personnel and professional quality of delivery personnel, and the use of delivery tools, namely, delivery boxes and delivery vehicles, will also affect the safety of food. Due to the particularity of food delivery, distribution personnel should choose equipment with good insulation performance and freshness, such as an EPP incubator existing in the market. Through investigation, $\mathrm{Ni}$ et al. [23] learned that microplastics were found in all takeout containers, and people who order takeout 4-7 times a week may ingest 12-203 microplastics through containers. In addition, the distribution box is not clean or disinfected, which will breed bacteria and bring food safety risks.

The positive feedback factors of the distribution risk of logistics distribution team include the unqualified health status of distribution personnel, the poor professional quality of distribution personnel, the nonstandard and poor hygiene of distribution box, and nonstandard distribution methods, while the negative feedback includes ensuring the health of distribution personnel, improving the professional quality of distribution personnel, standardizing the use of distribution boxes, and improving the hygiene of distribution boxes.

\subsection{Supervision Risk of $\mathrm{O} 2 \mathrm{O}$ Catering Platform. $\mathrm{O} 2 \mathrm{O}$} catering platform needs to strictly examine and supervise the settled merchants and food delivery personnel. If the $\mathrm{O} 2 \mathrm{O}$ catering platform fails to put its responsibilities and obligations in place, then it will bring risks to food safety.

The $\mathrm{O} 2 \mathrm{O}$ catering platform's inadequate qualification examination of settled merchants and safety management of takeout distribution is the positive feedback of risks, while the $\mathrm{O} 2 \mathrm{O}$ catering platform's strict examination of settled merchants' qualification and effective implementation of safety management of settled merchants and takeout distribution is the negative feedback of risks.

2.4. User Supervision Risk. The risk of user supervision is mainly analyzed from two aspects: the situation of userrights protection and the way users participate in supervision. In the process of Internet catering consumption, users purchase goods or services to generate income for businesses, so they have the right to supervise $\mathrm{O} 2 \mathrm{O}$ catering businesses and $\mathrm{O} 2 \mathrm{O}$ catering platforms. However, in fact, due to the lack of effective complaint or feedback channels, users cannot directly supervise the catering $\mathrm{O} 2 \mathrm{O}$ platform, and can only reflect the food safety problems existing in the catering $\mathrm{O} 2 \mathrm{O}$ or the problems in the distribution process through reports, thus further indicating that the $\mathrm{O} 2 \mathrm{O}$ catering platform has lax supervision and other phenomena. Li [24] found that online food safety has great hidden dangers, including the difficulty of safeguarding users' rights. 
Generally speaking, users are in a relatively weak position. The positive feedback factors of this kind of risk include the weak awareness of users' rights protection, the poor channels of users' rights protection, and the single way of users' participation in supervision, while the negative feedback factors include enhancing the users' awareness of rights protection, broadening channels of users' rights protection, and increasing users' participation in supervision.

2.5. Supervision Risks of Government Departments. The risks formed by government departments in supervision mainly come from three aspects: the lack of supervision awareness, the lack of supervision basis, and the poor implementation ability of government departments. Among them, the factors affecting the regulatory risks of government departments are divided into positive feedback factors and negative feedback factors. Positive feedback factors will increase the emergence of regulatory risks of government departments, mainly including the failure of government departments to perform their responsibilities, the failure of postrectification to truly implement regulatory awareness, the content of existing laws and regulations is not detailed, and the regulatory methods are backward. Negative feedback factors will reduce the emergence of supervision risks of government departments, including improving the regulatory awareness of government departments, improving relevant laws and regulations, and innovating regulatory methods.

Among them, positive feedback factors and negative feedback factors can be transformed into each other, and when the positive feedback factors in the system are greater than the negative feedback factors, risks will occur.

\section{Research Method}

This paper uses the method of system dynamics to analyze the risk formation principle in the process of food safety control in the catering $\mathrm{O} 2 \mathrm{O}$ distribution link and establishes a system dynamics model of food safety risk in the catering $\mathrm{O} 2 \mathrm{O}$ distribution link, thus providing a certain theoretical basis for the protection of food safety in the catering $\mathrm{O} 2 \mathrm{O}$ distribution link.

\subsection{Construction of Food Safety Risk Index System in Catering} O2O Distribution Link. According to the previous analysis, the five types of risks are further refined, a risk index system including primary risk factors and secondary risk factors is constructed, and each factor in the table is weighted by analytic hierarchy process. The specific weight results are shown in Table 1 below.

\subsection{Flow Diagram of System Model of the Food Safety Risk} Formation Mechanism in Catering O2O Distribution Link. Based on the index system of influencing factors of food safety risks in the catering $\mathrm{O} 2 \mathrm{O}$ distribution link, a system dynamics model of food safety risks in the catering $\mathrm{O} 2 \mathrm{O}$ distribution link is constructed, as shown in Figure 1.
Among them, the production of food products in $\mathrm{O} 2 \mathrm{O}$ catering enterprises is the source of risks; the risks caused by the distribution process of the logistics distribution team are the foundation, and the regulatory risks of government departments occupy the core position. It not only collects the regulatory information of users but also bears the risks brought by the supervision of the $\mathrm{O} 2 \mathrm{O}$ catering platform and the distribution of the logistics distribution team.

\subsection{Determination of Parameters and Boundary Risk Factor Values}

3.3.1. Initial Assignment of Model Simulation Variables. As can be seen from Figure 1, there are mainly 32 boundary points, of which some simulation variables and assignment processes and methods are shown in Table 2 below, while the remaining unlisted variables are determined by the expert scoring method. In the equations of system dynamics, A: auxiliary equation, L: horizontal equation, R: rate equation, $\mathrm{N}$ : initial value equation, and C: constant equation.

3.3.2. System Dynamics Equation Based on Index Weight. According to the index weight calculated by the analytic hierarchy process and combined with the modeling principle of system dynamics, the system dynamics equation of each risk factor is further determined. Because the five firstorder risk factors are not only affected by their subrisk factors but also interact with each other to produce risk. Therefore, it is necessary to adjust the weight based on the previous calculation. The dynamic equation of some factors is taken as an example:

(1) Food risk $=0.75 *$ production and processing risk $+0.25 *$ Food packaging risk.

(2) risk of distribution mode $=0.6667 *$ timeliness of the distribution mode $+0.3333 *$ standardization of the distribution mode.

(3) User participation supervision mode $=0.625 *$ User supervision feedback merchant situation $+0.1365 *$ User supervision platform situation $+0.2385 *$ User supervision logistics distribution team situation.

(4) Platform supervision risk $=0.6667 *$ platform's safety management of settled merchants $+0.3333 *$ platform's management of external sales and distribution $-0.07 *$ government department supervision risk.

(5) regulatory risk of government departments $=0.14 *$ Lack of regulatory awareness of government departments $+0.24 *$ Lack of regulatory basis of government departments $+0.62 *$ Poor implementation ability of government departments $+0.056 *$ User regulatory risk $+0.1043 *$ Logistics distribution team distribution risk $+0.2819 *$ Platform regulatory risk $+0.1458 *$ Food self-risk. 
TABLE 1: Food safety risk types and incentives in the catering $\mathrm{O} 2 \mathrm{O}$ distribution link.

\begin{tabular}{lc}
\hline Risk type & Primary risk factor \\
\hline & \\
& Food production and processing risk (A1) \\
O2O Catering Enterprise Food & 0.7500 \\
Self-risk (A) 0.1458 &
\end{tabular}

Food packaging risk (A2) 0.2500

Risk of delivery personnel (B1) 0.5396
Logistics Distribution Team Distribution Risk (B) 0.1043

O2O Catering Platform
Regulatory Risk (C) 0.2819

Risk of delivery tools (B2) 0.2970

Platform Audit Risk (C1) 0.6667

Regulatory Risk (C) 0.2819

Secondary risk factor

Work clothes are not clean in place $0.0500 \quad$ Code

Disinfection of appliances is not in place $0.1413 \quad \mathrm{U} 2$

Food cleaning is not in place 0.3993 U3

Rationality of food additive use $0.3139 \quad$ U4

The chef did not pay enough attention to the order U5 remarks 0.0955

Food packaging material $0.8333 \quad$ U6

There is no label on the packing box $0.1667 \quad$ U7

Health status of delivery personnel 0.6667 U8

Professional quality of distribution personnel 0.3333

Normalization of distribution box $0.2385 \quad$ U10

Sanitary status of distribution box $0.6250 \quad$ U11

Potential safety hazard of distribution vehicles 0.1365

Delivery timeliness 0.6667

Delivery Method Risk (B3) $0.1634 \quad$ Standardization of distribution mode $0.3333 \quad$ U14

The platform's qualification examination of settled U15

Platform Regulatory Risk (C2) 0.3333

User Rights Protection (D1) 0.2500

User Regulatory Risk (D) 0.0560

User Supervision Mode (D2) 0.7500

Lack of supervision awareness of government departments (E1) 0.1365

Government Regulatory Risk (E)

0.4120 Lack of regulatory basis for government
departments (E2) 0.2385

Poor implementation ability of government departments (E3) 0.6250 merchants 0.7500
The sampling situation of the platform on the settled merchants 0.2500

The safety management of the platform to the settled merchants 0.6667

Management of external sales and distribution of the platform 0.3333

User's awareness of safeguarding rights $0.6667 \quad$ U19

User rights protection channel $0.3333 \quad$ U20

User supervision feedback business situation 0.6250

User supervision platform situation $0.1365 \quad$ U22

User supervision of logistics distribution team 0.2385

Performance of duties by government departments 0.5396

Post-event rectification of government departments 0.1634

The rectification strength of the regulatory authorities 0.2970

There are fewer laws related to online ordering 0.6144

The existing legal content is not detailed 0.2684

Information asymmetry between government

departments, users and platforms 0.1172

The supervision mode lags behind 0.5396

Lack of professionalism in supervision 0.2970 Lack of Supervisors 0.1634
U16

$\mathrm{U} 17$

U18

$\mathrm{U} 21$

$\mathrm{U} 23$

$\mathrm{U} 24$

$\mathrm{U} 25$

$\mathrm{U} 26$

$\mathrm{U} 27$

$\mathrm{U} 28$

$\mathrm{U} 29$

$\mathrm{U} 30$

$\mathrm{U} 31$

U32

\section{Result and Discussion}

4.1. The Influence of Single Risk Factor Changes on Risk Output Variables. In this model, the food safety risk in catering $\mathrm{O} 2 \mathrm{O}$ distribution is mainly composed of five subrisk factors and their subdivided risk factors. Therefore, if the size of any of the subdivided factors is changed, other risks will also change. Taking the effective management of the $\mathrm{O} 2 \mathrm{O}$ catering platform's external sales and distribution as an example, the risk sizes of the effective management of the $\mathrm{O} 2 \mathrm{O}$ catering platform's external sales and distribution are set to be 0.8 and 0.2 , respectively. Line 1 indicates that the regulatory risk of the $\mathrm{O} 2 \mathrm{O}$ catering platform is 0.8 , and Line 2 indicates that the regulatory risk of the $\mathrm{O} 2 \mathrm{O}$ catering platform is 0.2 . And because the relationship between the risk subsystems in this model is a positive correlation, the greater the effective management value of the $\mathrm{O} 2 \mathrm{O}$ catering platform for external sales and distribution, the more unstable its value is, and the greater the impact on risk assessment. The result is shown in Figure 2 .

As the effective management of outbound sales and distribution on the $\mathrm{O} 2 \mathrm{O}$ catering platform drops from 0.8 to 


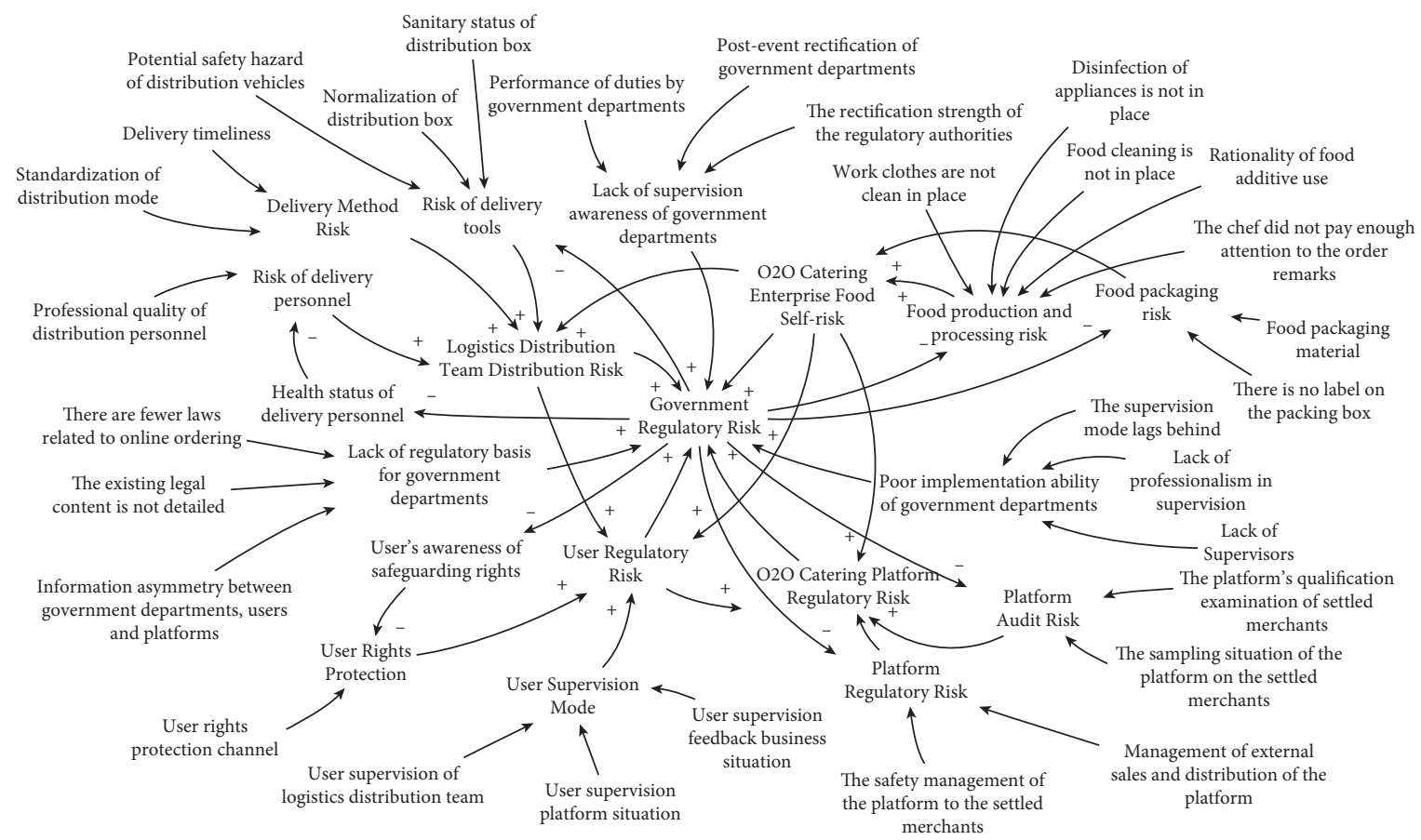

FIGURE 1: Flow diagram of system model of the food safety risk formation mechanism in the catering O2O distribution link.

TABle 2: Assignment table of model simulation variables.

\begin{tabular}{|c|c|c|c|}
\hline Variable name & $\begin{array}{l}\text { Variable } \\
\text { type }\end{array}$ & Assignment & Initial data source and processing method \\
\hline $\begin{array}{l}\text { O2O Catering Enterprises' Food } \\
\text { Products' Own Risks (initial value) }\end{array}$ & $\mathrm{L}$ & 0.5 & $\begin{array}{l}\text { Evaluate the current situation of food risk management in } \mathrm{O} 2 \mathrm{O} \\
\text { catering enterprises and determine the conversion by combining } \\
\text { expert scoring method with the analytic hierarchy process }\end{array}$ \\
\hline $\begin{array}{l}\text { Distribution Risk of Logistics } \\
\text { Distribution Team (initial value) }\end{array}$ & $\mathrm{L}$ & 0.4 & $\begin{array}{l}\text { On-the-spot interview, data investigation, and finally through expert } \\
\text { scoring method, a conversion is determined }\end{array}$ \\
\hline $\begin{array}{l}\text { Regulatory Risk of O2O Catering } \\
\text { Platform (initial value) }\end{array}$ & $\mathrm{L}$ & 0.6 & $\begin{array}{l}\text { Evaluate the current situation of the risk management of } \mathrm{O} 2 \mathrm{O} \text { catering } \\
\text { platform, and determine the conversion by combining expert scoring } \\
\text { method with analytic hierarchy process }\end{array}$ \\
\hline User Supervision Risk (initial value) & $\mathrm{L}$ & 0.2 & $\begin{array}{l}\text { On-the-spot interview, data investigation, and finally through expert } \\
\text { scoring method, a conversion is determined }\end{array}$ \\
\hline $\begin{array}{l}\text { Regulatory Risks of Government } \\
\text { Departments (initial value) }\end{array}$ & $\mathrm{L}$ & 0.7 & $\begin{array}{c}\text { Evaluate the current situation of risk management in government } \\
\text { departments, combine expert scoring method with analytic hierarchy } \\
\text { process, and convert and determine }\end{array}$ \\
\hline Rationality of the use of food additives & $\mathrm{C}$ & 0.0317 & $\begin{array}{c}\text { Data investigation, through expert scoring method, and then take the } \\
\text { average value to determine }\end{array}$ \\
\hline Food packaging materials & $\mathrm{C}$ & 0.0255 & $\begin{array}{c}\text { Data investigation, through expert scoring method, and then take the } \\
\text { average value to determine }\end{array}$ \\
\hline User rights protection channels & $\mathrm{C}$ & 0.0155 & $\begin{array}{c}\text { Data investigation, through expert scoring method, and then take the } \\
\text { average value to determine }\end{array}$ \\
\hline $\begin{array}{l}\text { Users supervise and feedback the } \\
\text { business situation }\end{array}$ & $\mathrm{C}$ & 0.0112 & $\begin{array}{c}\text { Data investigation, through expert scoring method, and then take the } \\
\text { average value to determine }\end{array}$ \\
\hline User monitoring platform situation & $\mathrm{C}$ & 0.0151 & $\begin{array}{c}\text { Data investigation, through expert scoring method, and then take the } \\
\text { average value to determine }\end{array}$ \\
\hline $\begin{array}{l}\text { Users supervise the logistics } \\
\text { distribution team }\end{array}$ & $\mathrm{C}$ & 0.0146 & $\begin{array}{c}\text { Data investigation, through expert scoring method, and then take the } \\
\text { average value to determine }\end{array}$ \\
\hline $\begin{array}{l}\text { Performance of duties by government } \\
\text { departments }\end{array}$ & $\mathrm{C}$ & 0.0306 & $\begin{array}{c}\text { Data investigation, through expert scoring method, and then take the } \\
\text { average value to determine }\end{array}$ \\
\hline $\begin{array}{l}\text { Rectification of government } \\
\text { departments after the event }\end{array}$ & $\mathrm{C}$ & 0.0178 & $\begin{array}{c}\text { Data investigation, through expert scoring method, and then take the } \\
\text { average value to determine }\end{array}$ \\
\hline $\begin{array}{l}\text { The rectification efforts of the } \\
\text { regulatory authorities }\end{array}$ & $\mathrm{C}$ & 0.0244 & $\begin{array}{c}\text { Data investigation, through expert scoring method, and then take the } \\
\text { average value to determine }\end{array}$ \\
\hline
\end{tabular}



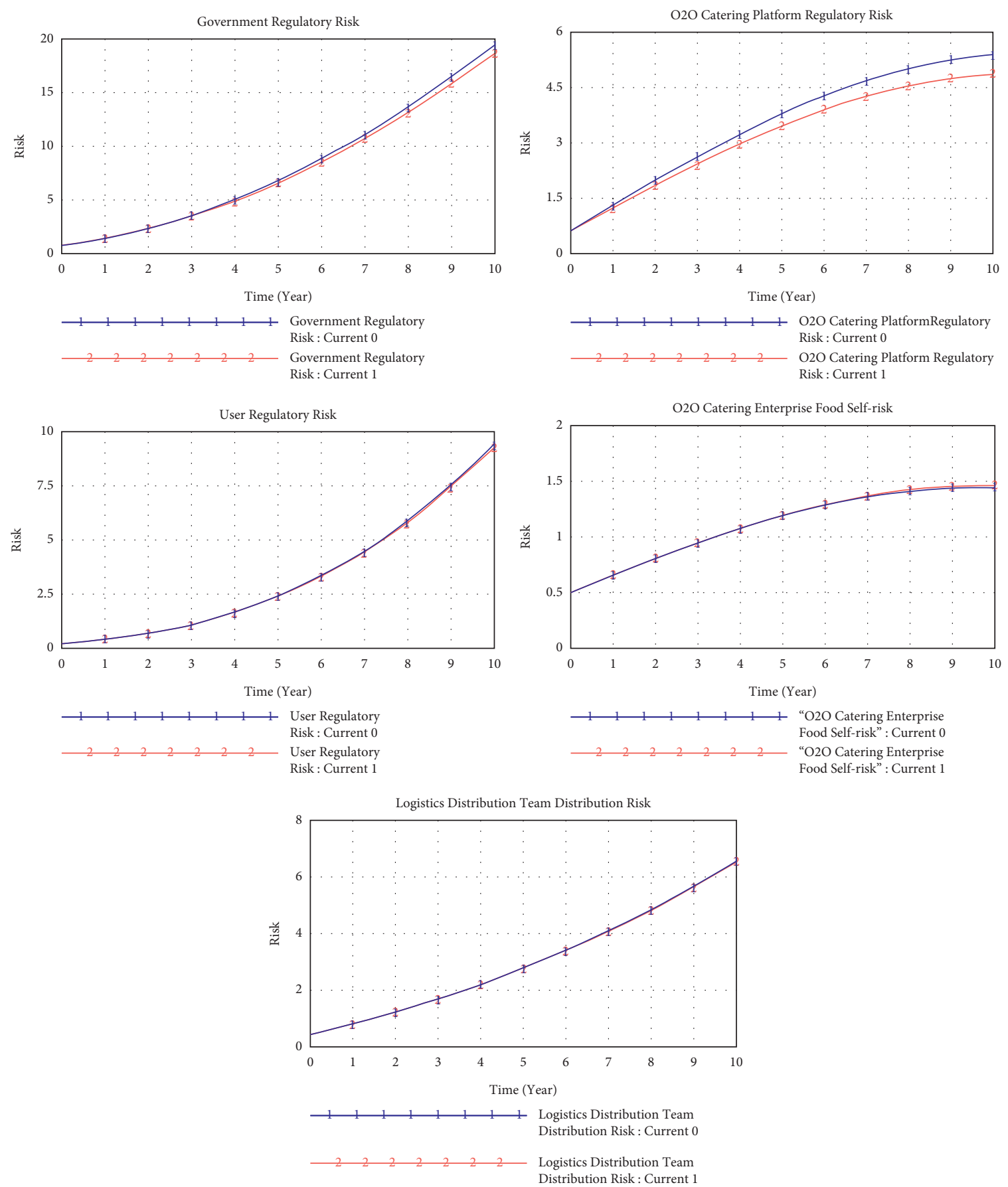

Figure 2: Simulation results of effective management changes of the $\mathrm{O} 2 \mathrm{O}$ catering platform for external sales and distribution to different risk factors.

0.2 , the risks of the five subjects all show a trend of rising at the beginning and then gradually flattening out. With the reduction of risk factors, the regulatory risks of government departments and $\mathrm{O} 2 \mathrm{O}$ catering platforms have been significantly controlled compared to the original, while the risk changes of the other three subjects are not obvious. This also indicates to some extent that when risks in the system keep rising, the supervision of government departments and $\mathrm{O} 2 \mathrm{O}$ catering platforms plays an extremely important role in timely controlling the expansion of risks.
4.2. The Influence of Different Risk Factors on the Same Risk Output Variable. This paper will take the effectiveness of the $\mathrm{O} 2 \mathrm{O}$ catering platform's external distribution management (ME) and the influence of the same proportional change of the distribution personnel's professional quality (PQDP) on the distribution risk output of the logistics distribution team as an example. Set the effectiveness risk of the $\mathrm{O} 2 \mathrm{O}$ catering platform's distribution management for external sales to be 0.2 and 0.8 , respectively, and the risk of professional quality of distribution personnel to be 0.2 and 0.8 , respectively. The 
TABLE 3: Comparison of the impact of the effectiveness of catering platform sales distribution management and the professional quality of distribution personnel on the distribution risk of logistics distribution team.

\begin{tabular}{lccccccccccc}
\hline Interval (Year) & Initial value & 1 & 2 & 3 & 4 & 5 & 6 & 7 & 8 & 9 & 10 \\
\hline ME 0.8 & 0.4 & 0.7802 & 1.1996 & 1.6637 & 2.1779 & 2.7473 & 3.3764 & 4.0696 & 4.8305 & 5.6622 & 6.5675 \\
ME 0.2 & 0.4 & 0.7802 & 1.1996 & 1.6632 & 2.1761 & 2.7428 & 3.3676 & 4.0544 & 4.8067 & 5.6275 & 6.5191 \\
PQDP 0.8 & 0.4 & 0.8642 & 1.3676 & 1.9155 & 2.5133 & 3.1659 & 3.8779 & 4.6533 & 5.4960 & 6.4092 & 7.3956 \\
PQDP 0.2 & 0.4 & 0.7562 & 1.1516 & 1.5913 & 2.0803 & 2.6232 & 3.2244 & 3.8877 & 4.6166 & 5.4141 & 6.2826 \\
\hline
\end{tabular}

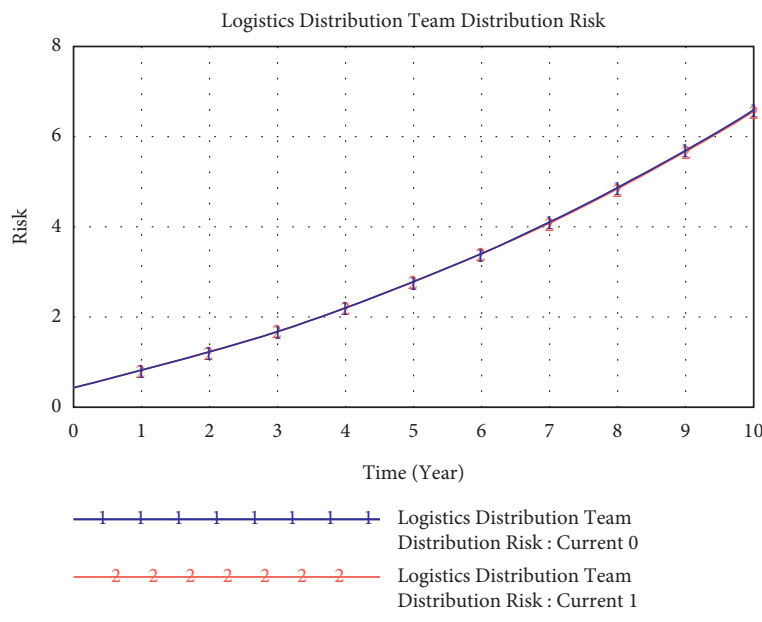

(a)

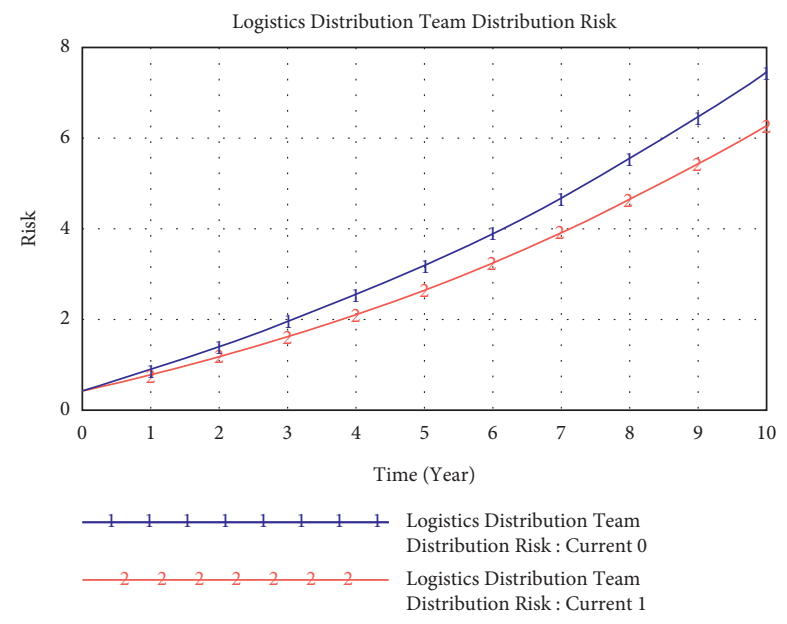

(b)

FiguRE 3: Risk simulation results of management effectiveness (a) and professional quality of distribution personnel (b) on distribution personnel of logistics distribution team.

change of distribution risk of logistics distribution team affected by it is observed. Table 3 shows the simulation result data in detail, and Figure 3 is an intuitive embodiment of it.

It can be seen from Table 3 and Figure 3 that when the effectiveness of the $\mathrm{O} 2 \mathrm{O}$ catering platform's outbound distribution management and the professional quality of distribution personnel rise from 0.2 to 0.8 , respectively, the risk of distribution personnel of logistics distribution team changes to varying degrees.

\section{Conclusion}

Aiming at the different subjects involved in the process of catering $\mathrm{O} 2 \mathrm{O}$ distribution, this paper identifies the possible risks faced by different subjects in the process of catering $\mathrm{O} 2 \mathrm{O}$ distribution and determines five risk factors: $\mathrm{O} 2 \mathrm{O}$ catering enterprise's own risk, logistics distribution team's distribution risk, $\mathrm{O} 2 \mathrm{O}$ catering platform supervision risk, user supervision risk, and government department supervision risk. In addition, this paper analyzes the correlation between these five risk factors by means of the system dynamics principle, constructs the food safety risk system analysis flow diagram of catering $\mathrm{O} 2 \mathrm{O}$ distribution link, and carries out computer simulation experiments. The following conclusions are drawn:

(1) The simulation results of the first experiment show that the five risk factors of food safety risk in catering $\mathrm{O} 2 \mathrm{O}$ distribution constitute a feedback relationship with each other. When the risk occurs, the government regulatory risk and $\mathrm{O} 2 \mathrm{O}$ catering platform regulatory risk will rapidly expand the risk of the whole system. Therefore, government departments and the $\mathrm{O} 2 \mathrm{O}$ catering platform should do a good job in daily supervision, rather than wait until the risk rises or causes serious impact before taking measures, which can also reduce the risks faced by the other three subjects to a certain extent.

(2) According to the results of the second experimental simulation, it is found that changing a certain risk influencing factor or changing different risk influencing factors in the same proportion will have a different impact on different risk subjects. Therefore, when a certain risk occurs in the system, the proportion of risk factors can be changed so as to understand its impact on the risks of different subjects and then formulate countermeasures.

5.1. Theoretical Contributions. Firstly, this paper enriches the literature on food safety risks in catering $\mathrm{O} 2 \mathrm{O}$ distribution. On the one hand, there are few studies on the food safety risk of catering $\mathrm{O} 2 \mathrm{O}[25,26]$. Through literature reading, this research divides the possible risks of food safety in catering $\mathrm{O} 2 \mathrm{O}$ distribution into five risk factors: $\mathrm{O} 2 \mathrm{O}$ catering enterprise's own food risk, logistics distribution team distribution risk, $\mathrm{O} 2 \mathrm{O}$ catering platform supervision 
risk, user supervision risk, and government department supervision risk, which improves the research on catering $\mathrm{O} 2 \mathrm{O}$ food safety risk. On the other hand, this research further enriches the research methods of food safety risk. According to the theory of system dynamics, the occurrence of risk is not independent, but the interaction of various subjects is involved. However, at present, few literature research the risks faced by food safety in catering $\mathrm{O} 2 \mathrm{O}$ distribution from a systematic perspective [27]. Therefore, the research results of this paper are a response and supplement to the existing literature.

5.2. Managerial Implications. This research also provides some practical enlightenment for the supervision and management of government departments, catering $\mathrm{O} 2 \mathrm{O}$ platform, and enterprises. Through the research, it is found that the food safety risk in catering $\mathrm{O} 2 \mathrm{O}$ distribution is not only from the quality of $\mathrm{O} 2 \mathrm{O}$ catering enterprises but also closely related to the production, processing, packaging, and distribution of the catering $\mathrm{O} 2 \mathrm{O}$ food. It is a relatively complex system. Therefore, all participants should consider risks from a systematic perspective and clarify their respective responsibilities and obligations. For example, $\mathrm{O} 2 \mathrm{O}$ catering enterprises should strengthen the control of kitchen hygiene and personnel, and the platform should strictly review the entry qualification of enterprises so as to minimize the occurrence of food risks and to truly promote the orderly and healthy development of online catering services in China [28].

\section{Data Availability}

The data used to support the findings of this study are included within the article.

\section{Conflicts of Interest}

The authors declare that they have no conflicts of interest.

\section{Acknowledgments}

The paper was supported by the Beijing Social Science Fund (No. 17GLC050), Premium Funding Project for Academic Human Resources Development in the Beijing Union University (No. BPHR2020CS05), Key Projects of Scientific Research Plan of Beijing Municipal Education Commission (No. SZ202111417021), the Academic Research Projects of Beijing Union University (No. JS10202006), and Teaching Innovation Course Construction Project in Beijing Union University (No. 12205561107-132).

\section{References}

[1] D. J. Min and C. J. Fei, "Research on the impact of webcast on customer trust of catering $\mathrm{O} 2 \mathrm{O}$ takeout," Operations Research and Management, vol. 30, no. 5, pp. 221-226, 2021.

[2] Z. Z. Xiang and S. K. Ran, "Research on the safety of takeout food on O2O platform," Food Industry, vol. 38, no. 1, pp. 218-221, 2017.
[3] M. Peng, S. Chen, L. Jing, and X. X. Fei, "Decreasing consumers' risk perception of food additives by knowledge enhancement in China," Food Quality \& Preference, vol. 79, 2020.

[4] W. Xue and G. C. Bo, "Food safety governance in cross-border e-commerce," Food Industry, vol. 42, no. 2, pp. 340-346, 2021.

[5] L. D. Wei and F. Wei, "Benefit game and differentiation decision-making of food quality and safety -- a comparative study based on online and offline," Financial Science, vol. 6, pp. 70-82, 2019.

[6] L. Y. Bo, W. G. Feng, and Z. Ning, "Research and thinking on establishing and improving China's food safety assurance system," Chinese Journal of Food, vol. 19, no. 12, pp. 6-13, 2019.

[7] L. Zhao, C. Wang, H. Gu, and C. Yue, "Market incentive, government regulation and the behavior of pesticide application of vegetable farmers in China," Food Control, vol. 85, pp. 308-317, 2018.

[8] W. G. Ge, "Current situation and measures of online food supervision and sampling," Modern Food, vol. 8, pp. 147-149, 2020.

[9] H. Lan, Y. X. Rong, and Z. X. Cai, "Research on food safety status of online ordering platform based on negative comments," Business and Economic Research, vol. 9, pp. 92-95, 2019.

[10] Z. Xi, "Legal liability system and supervision mode of online shopping food safety," Food Industry, vol. 41, no. 2, pp. 213-216, 2020.

[11] K. Z. Yong, G. X. Lin, and Y. H. Xiong, "Analysis on collaborative governance system of online shopping food safety," Food Science, vol. 40, no. 5, pp. 339-345, 2019.

[12] J. Jie, “'Internet plus' food pattern, security supervision dilemma and strategy research," China Health Policy Research, vol. 11, no. 5, pp. 28-32, 2018.

[13] S. J. Shuang, Y. Chao, Y. Z. Dong, G. M. Dan, W. Z. Zhen, and R. X. Mei, "Food safety issues and regulatory suggestions for online catering services," Food industry, vol. 41, no. 11, pp. 275-278, 2020.

[14] W. E. Quan, L. X. Yu, L. X. Wei et al., "Application and prospect of insulated self-contained cabinet in takeout distribution industry in the Internet era," China Market, vol. 17, pp. 161-162, 2019.

[15] R. Q. Qian, "Research and analysis on traffic safety problems in real-time distribution (takeout) industry," China Storage and Transportation, vol. 11, pp. 189-190, 2020.

[16] G. X. Yi, S. Y. Xin, T. M. Hong, and Q. Y. Gui, "Problems and countermeasures in the current takeout distribution mode," China Business Theory, no. 03, pp. 32-33, 2019.

[17] L. Y. Sheng and L. Qing, "Study on influencing factors and action mechanism of takeout food safety based on grounded theory," Business Research, vol. 10, pp. 11-18, 2019.

[18] W. J. Hua, W. Heng, and S. Jun, "Food safety supervision strategy from the perspective of ordering platform," Economics and Management, vol. 34, no. 03, pp. 79-85, 2020.

[19] M. Ying, W. Chen, H. J. Jing, L. J. Chu, and L. Jia, "Information search behavior of consumers' food safety risk perception based on SD-SEM model," System Engineering Theory and Practice, vol. 37, no. 04, pp. 962-971, 2017.

[20] Y. Zhang, E. Isaeva, and Á. Rocha, "Food safety risk intelligence early warning based on support vector machine," Journal of Intelligent \& Fuzzy Systems, vol. 38, no. 06, pp. 6957-6969, 2020. 
[21] Z. H. Bang, W. D. Yuan, and M. X. Ran, "Media presentation risk and prevention based on," Food Supply Chain" Journal of Information, vol. 39, no. 10, pp. 115-120, 2020.

[22] C. Disanto, G. Celano, A. Dambrosio et al., "Food safety in collective catering: knowledge, attitudes and correct application of GHP/GMP knowledge among foodservice workers," Italian Journal of Food Safety, vol. 9, no. 4, pp. 201-205, 2020.

[23] D. F. Ni, C. H. Wen, Z. Qun, C. Q. Qing, and S. H. Hong, "Microplastics in take-out food containers," Journal of Hazardous Materials, vol. 399, Article ID 122969, 2020.

[24] Z. Li, "Safety problems and regulatory countermeasures of online shopping food in China," Agricultural Engineering, vol. 8, no. 12, pp. 62-64, 2018.

[25] S. Y. Zhong, S. X. Rong, Z. Jian, L. Li, Z. Q. Xia, and L. Yao, "Regional character, restaurant size, and food safety risk: evidence from food safety violation data in Gansu Province, China," Journal of Food Protection, vol. 83, no. 4, pp. 677-685, 2020.

[26] X. G. Chong, "Risk assessment of food safety supervision: theoretical definition, mechanism design and implementation strategy," Social Science Front, vol. 10, pp. 181-189, 2021.

[27] W. D. Hua, M. Jiao, and Z. Y. Xin, "Game analysis on the governance of takeout food safety," Food Industry, vol. 40, no. 5, pp. 251-255, 2019.

[28] T. Dan, T. J. Fu, and R. Yue, "Optimization of promotion strategy for the elasticity of real-time distribution service system under $\mathrm{O} 2 \mathrm{O}$ mode," System Engineering Theory and Practice, vol. 41, no. 2, pp. 310-318, 2021. 